\title{
Peripherality as key to understanding climate-associated risk and resilience for Pacific island communities
}

Patrick Nunn ${ }^{\mathrm{a}}{ }^{*}$, Eugene Joseph ${ }^{\mathrm{b}}$, Isoa Korovulavula ${ }^{\mathrm{c}}$, and Roselyn Kumar a

a School of Social Sciences, University of the Sunshine Coast, Australia

$b$ Conservation Society of Pohnpei, Federated States of Micronesia

c Institute of Applied Sciences, University of the South Pacific, Fiji Islands

* Corresponding author. Email: pnunn@usc.edu.au

\section{ABSTRACT}

To address the lack of effective sustained interventions for climate-change adaptation in Pacific island communities, a study to capture individual community risk and resilience profiles using peripherality was undertaken. Based on questionnaires completed in 73 communities, three peripherality indices were tested and refined and demonstrated to adequately capture various things such as community exposure to climate change and autonomous community coping capacity. The implications of this study are many, not least in helping define national policy towards greater self-sufficiency but also in helping design more effective and sustainable external interventions for future climate change adaptation.

\section{INTRODUCTION}

For several decades it has been clear that most externally-designed and funded interventions for climate-change adaptation in Pacific island communities have failed to be effective or sustained (Nunn \& Kumar, 2018; Piggott-McKellar, McNamara, Nunn, \& Watson, 2019), a situation that is worrying considering recent accelerations in climate change and revised projections for the future (Nurse et al., 2014; World Meteorological Organization, 2019 ). This situation requires that past methods of addressing climate risk in such communities are revisited, especially through acknowledging the diversity of community exposure. In addition, it is clear that most past interventions have ignored culturally-grounded community resilience in favour of global solutions, a situation that is increasingly acknowledged

\section{KEYWORDS}

Autonomous coping capacity, Climate change, Dependency, Developing countries, Peripherality, Traditional/indigenous knowledge

\section{DOI}

https://doi.org/10.30852/sb.2019.888

\section{DATES}

Received: 25 July 2019

Published (online): 6 December 2019

Published (PDF): 12 December 2019

\section{HIGHLIGHTS}

» Peripherality captures community diversity.

» Peripherality allows community risk and resilience profiling.

» Peripherality measurements can optimize future interventions. as unsustainable (Granderson, 2017; Makondo \& Thomas, 2018; Nalau et al., 2018; Nunn, Runman, Falanruw, \& Kumar, 2017).

This study sought to inform improved interventions for climate change adaptation in developing-world communities by addressing the latter two points: first by demonstrating the diversity of community exposure rather than assuming that "one-size-fits-all" and, second, by showing the existence and diversity of culturally-grounded community coping in communities. In these ways, a better understanding of risk and resilience among these communities has been obtained.

\section{METHODOLOGY}

For 73 communities involving 630 people (47\% male, $53 \%$ female) in the island countries of the 
Federated States of Micronesia (FSM) and Fiji, diversity was researched using peripherality, the notion that communities are arranged in such island groups along a continuum from (developmental and economic) cores to peripheries (Nunn \& Kumar, 2018). Data for measuring peripherality were obtained from in-depth community interviews (based on 97 questions) and were then analysed to derive three "peripherality indices" that could then be used to predict particular aspects of risk and resilience for such communities (details and questionnaire in Nunn \& Kumar, 2019b).

Initial data were obtained from 15 Fijian communities in Bua Province, data that allowed development of preliminary peripherality indices that were then re-applied to those communities and others in northern Fiji to ascertain their efficacy in measuring risk and resilience. Peripheral communities are those where the time/ cost/effort needed to travel to the closest urban centre (core) often reduces use of its facilities by community residents and, conversely, leads such communities to be more autonomous. The final three peripherality indices developed were then tested elsewhere in Fiji and in FSM and their effectiveness confirmed. These indices refer to Geography (Index 1), Population and Employment (Index 2), and Tradition and Global Awareness (Index 3) and could be calculated through answers to 15 context-specific questions.

All data collection was carried out with appropriate ethics approvals and in the vernacular languages of the target populations, mostly by the four authors. Results of this study have been conveyed back to key community stakeholders and disseminated internationally through publications and conference presentations.

\section{RESULTS AND DISCUSSION}

This study has produced results that are relevant to future climate change adaptation at various levels, including community and subnational, national and regional, and international and global. The nature of these results at each level are illustrated through the following three subsections, followed by a discussion that highlights the relevance of this study beyond the countries studied.

\subsection{Results at community and subnational level}

The three peripherality indices were applied to capture the risk/resilience profile of particular groups of communities in different parts of FSM and Fiji. In 14 communities in Bua (Fiji), peripherality was used to "predict" community "preferences" for western/traditional medicine (Figure 1), a preference for western medicine, which is expensive and difficult to access

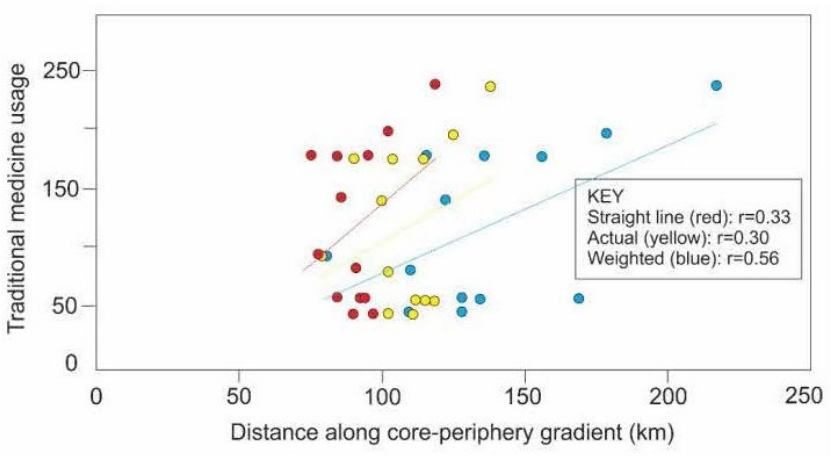

FIGURE 1. Use of peripherality to predict traditional medicine usage among communities of Bua (Fiji Islands).

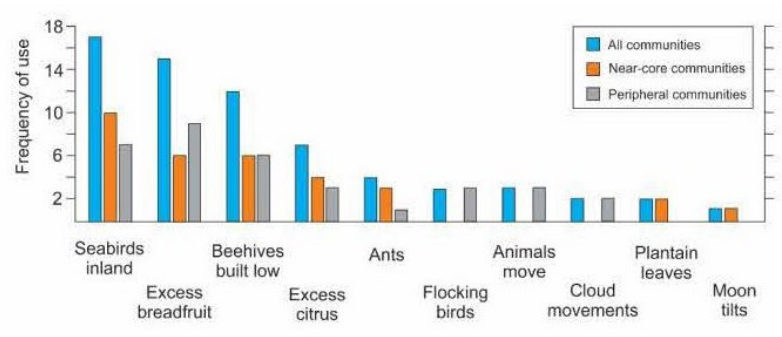

FIGURE 2. Use of traditional disaster precursors predicted by peripherality among communities along the cross-island road, Viti Levu Island (Fiji).

and consequently regarded as less sustainable than a preference for traditional medicine (Nunn \& Kumar, 2019a; Nunn \& Kumar 2019b). The word "preference" is used here to indicate dominant community usage of medicine type, not necessarily their desire/trust of this. As detailed in Korovulavula, Nunn, Kumar and Fong (in review), the inappropriate use of traditional remedies for new ailments (like NCDs) is an example of the failure of development in contexts such as those studied.

Similar research applied peripherality indices to 11 communities along the cross-island road on Viti Levu Island (Fiji) to capture autonomous community coping capacity (Korovulavula et al., in review). This shows up well as the understanding of traditional disaster precursors, a form of culturally-grounded knowledge that is considered suitable as a basis for future intervention combined with global knowledge (Figure 2).

In both these examples, the measurement of community peripherality within a group of rural Pacific island communities has shown their diversity and, most importantly, separated those communities that are most at risk from climate change (because they are least autonomous and more dependent) from those communities that are most resilient (because they are autonomous or have the potential-through the existence of traditional coping - to be so). These examples therefore illustrate how peripherality can be used to quickly and easily assess community diversity and therefore inform 
the optimal design and delivery of interventions for climate change adaptation.

\subsection{Results at national and regional level}

The acceleration of climate change, especially - in a small-island context - the accelerating sea-level rise in the Pacific (Nerem et al., 2018), is likely to lead to a situation within the next few decades where large numbers of rural communities, especially along coasts, will need to be assisted to sustain themselves in the face of unprecedently rapid climate change. Interventions will likely be underfunded and will therefore depend for their success on differing degrees of autonomous community coping. Results show that more resilient communities are likely to be those with existing traditional/indigenous knowledge, be it about traditional healthcare or disaster preparation, while more risk-exposed (less resilient) communities are likely to be those that have "lost" most of their traditional/indigenous knowledge and are almost wholly dependent on outside assistance for their sustainability. Peripherality measurements of the kind described in this study will allow the rapid capture of community diversity, allowing national and regional planners to quickly understand which communities are more in need of external help in order to sustain themselves and which communities are better able to cope autonomously with climate change challenges.

The use of peripherality to capture community needs is also something that national (government) and regional planners could use now to prepare communities for the future. Trends of increasing dependency on external/western solutions to a range of developmental challenges (which are costly and often unreliable) are unsustainable, both because of the growing inability of island countries to afford them but also because their supply is likely to decline in the future. A recent study (Nunn \& Kumar, 2019a), arising from the current project, argues that trends of increasing dependency by island countries (and developing nations more broadly) on other countries for climate change adaptation are unsustainable because, within a few decades, the costs of domestic adaptation to climate change for these countries will become so great that they will be unable to afford to be as generous as they are today towards their poorer island neighbours. The likelihood of this underlines the urgency for island nations (and other developing countries) to become more self-reliant, especially at meeting the challenges of climate change adaptation, or risk societal breakdown as livelihood loss multiplies over the next few decades.

\subsection{Results at international and global level}

Similar comments refer to the international/global level but here the results of this study are considered more to be instructive rather than directional. Many of the failed interventions for climate change adaptation in Pacific island countries (and elsewhere) have been designed and costed elsewhere, meaning that they are not always well aligned to the actual situation to which they are applied. For example, hard structures (like seawalls) for shoreline protection may often be constructed within the context of a particular project but, when they require maintenance (or need rebuilding), it is assumed that beneficiary communities will do so. Often these communities lack the necessary resources, so the interventions fail and may even prove maladaptive.

Given the growing urgency of making sure that future climate change interventions in rural communities in the Pacific Islands (and elsewhere) are both effective and sustainable, it is considered important that international/global stakeholders are better educated about target-community needs (risk profile) and autonomous coping ability (contributing to resilience). Use of peripherality indices to rapidly measure risk-resilience in these contexts would allow better-informed and more sustainable interventions in the future.

\section{CONCLUSION}

Peripherality measurements of rural Pacific island communities allow their risk and resilience profiles to be readily and accurately determined. This provides a ready tool for measuring community diversity in developing-country contexts. This is considered essential in order to optimally tailor future interventions for climate change adaptation so that these are effective and sustainable.

\section{ACKNOWLEDGEMENTS}

The researchers are grateful to APN for funding and project support. Without the selfless and generous cooperation and hospitality of the people of the $73 \mathrm{com}$ munities we studied, this research would not have been possible.

\section{REFERENCES}

Granderson,A.A.(2017). The role of traditional knowledge in building adaptive capacity for climate change: Perspectives from Vanuatu. Weather Climate and Society, 9(3), 545-561. doi:10.1175/wcas-d-16-0094.1 Korovulavula, I., Nunn, P. D., Kumar, R., \& Fong, T. (in review). Peripherality as key to understanding opportunities and needs for effective and sustainable 
climate-change adaptation: A case study from Viti Levu Island, Fiji. Climate and Development.

Makondo, C. C., \& Thomas, D. S. G. (2018). Climate change adaptation: Linking indigenous knowledge with western science for effective adaptation. Environmental Science \& Policy, 88, 83-91. doi:10.1016/j.envsci.2018.06.014

Nalau, J., Becken, S., Schliephack, J., Parsons, M., Brown, C., \& Mackey, B. (2018). The Role of Indigenous and Traditional Knowledge in Ecosystem-Based Adaptation: A Review of the Literature and Case Studies from the Pacific Islands. Weather Climate and Society, 10(4), 851-865. doi:10.1175/ wcas-d-18-0032.1

Nerem, R. S., Beckley, B. D., Fasullo, J. T., Hamlington, B. D., Masters, D., \& Mitchum, G. T. (2018). Climatechange-driven accelerated sea-level rise detected in the altimeter era. Proceedings of the National Academy of Sciences of the United States of America, 115(9), 2022-2025. doi:10.1073/pnas.1717312115

Nunn, P. D., \& Kumar, R. (2018). Understanding climate-human interactions in Small Island Developing States (SIDS): Implications for future livelihood sustainability. International Journal of Climate Change Strategies and Management, 10(2), 245-271. doi:10.1108/IJCCSM-01-2017-0012

Nunn, P. D., \& Kumar, R. (2019a). Cashless adaptation to climate change in developing countries: Unwelcome yet unavoidable? One Earth, 1, 31-34. doi:10.1016/j. oneear.2019.08.004

Nunn, P. D., \& Kumar, R. (2019b). Measuring peripherality as a proxy for autonomous community coping capacity: A case study from Bua Province, Fiji Islands, for improving climate change adaptation. Social Sciences, 8(8), 225. doi:10.3390/socsci8080225

Nunn, P. D., Runman, J., Falanruw, M., \& Kumar, R. (2017). Culturally grounded responses to coastal change on islands in the Federated States of Micronesia, northwest Pacific Ocean. Regional Environmental Change, 17(4), 959-971. doi:10.1007/ s10113-016-0950-2

Nurse, L., McLean, R., Agard, J., Briguglio, L. P., Duvat, V., Pelesikoti, N., ... Webb, A. (2014). Small islands. In V. R. Barros, C. B. Field, D. J. Dokken, M. D. Mastrandrea, K. J. Mach, T. E. Bilir, M. Chatterjee, K. L. Ebi, Y. O. Estrada, R. C. Genova, B. Girma, E. S. Kissel, A. N. Levy, S. MacCracken, P. R. Mastrandrea, \& L. L. White (Eds.), Climate Change 2014: Impacts, Adaptation, and Vulnerability. Part B: Regional Aspects. Contribution of Working Group II to the Fifth Assessment Report of the Intergovernmental Panel on Climate Change. Cambridge: Cambridge University Press.
Piggott-McKellar, A., McNamara, K., Nunn, P. D., \& Watson, J. (2019). What are the barriers to successful community-based climate change adaptation? A review of grey literature. Local Environment, 24(4), 374-390. doi:10.1080/13549839.2019.1580688

World Meteorological Organization. (2019). WMO Statement on the State of the Global Climate in 2018. Geneva: WMO. 